\title{
Palabras de la presidenta del Colegio Colombiano de Terapia Ocupacional en el $6^{\circ}$ Encuentro Colombiano de Estudiantes de Terapia Ocupacional ${ }^{1}$
}

\author{
Solángel García Ruiz²
}

Buenos días a todas y todos.

Quiero agradecer a la Red de Estudiantes de Terapia Ocupacional de Colombia por la invitación que nos hace, como Colegio Colombiano de Terapia Ocupacional, para abrir este evento hoy y compartir algunas reflexiones.

Quiero decirles que ha sido muy difícil escribir estas palabras y buscar la inspiración, no porque no tenga que decir, sino porque no se qué decir. Es como si mi cuerpo, mi ser y mis palabras hubiesen quedado en el vacío, en ese vacío en el que quedamos como país, el mismo que no sentía desde aquellas semanas de 1985, cuando un día el Palacio de Justicia dejó de existir con toda su gente adentro, y Armero, con toda su gente adentro, desapareció del mapa; esos trágicos días en los que, seguramente, muchos de ustedes no habían nacido.
Esta semana que pasó tuve la misma sensación. Esta vez fue luego de un NO a la paz y de un Premio Nóbel de Paz, de sentir la incertidumbre de país: de ese país que está fuera de las fronteras de las ciudades; de ese país que llora y ríe, que reclama por el perdón, la reconciliación y la paz; de ese país donde todo puede pasar; de ese país que al parecer perdía su rumbo; de ese país que un día García Márquez describió como Macondo.

Entonces, mis reflexiones transitan al lugar de los estudiantes, incluso a mi lugar como estudiante, al papel de ellos y de sus movimientos sociales en la historia política de este país.

Los estudiantes, en cualquier lugar del mundo, buscan sociedades más democráticas. Como en Francia, en el 68, durante las protestas por la crisis económica; o en Estados Unidos, con el

\footnotetext{
${ }^{1}$ El $6^{\circ}$ Encuentro Colombiano de Estudiantes de Terapia Ocupacional, Viviendo la TO desde Adentro, se realizó en Bogotá los días 13, 14 y 15 de octubre de 2016. Estas palabras se pronunciaron durante la apertura de este evento, la cual se llevó a cabo en la Quinta de Mutis, Escuela de Ciencias de la Salud, de la Universidad del Rosario.

${ }^{2}$ Terapeuta Ocupacional. Magíster en Desarrollo Social y Educativo. Presidenta del Consejo Directivo Nacional, Colegio Colombiano de Terapia Ocupacional. Bogotá, Colombia. solecita_co@yahoo.com
} 
lema de amor y paz; o en Berlín, repudiando la guerra en Vietnam, la moral sexual y la herencia nazi; o en Chile, con el movimiento de los pingüinos por el alza de las matrículas (Santamaría Sanabria, s.f.), y así, muchos más.

Cuenta el profesor Mauricio Archila (2012), que en casi sesenta años los estudiantes universitarios han sido parte de la historia política colombiana. Los movimientos estudiantiles han pasado de luchar por las reformas universitarias, a mediados del siglo pasado, a querer cambiar el país con sentido más incluyente, democrático y nacionalista; también señala que el Estado y los sectores dominantes, a finales del siglo pasado y comienzos de este, quisieron criminalizar a los estudiantes con el fin de apagar su protesta. Sin embargo, en esta segunda década de los dos mil, parece que las cenizas toman fuerza y es cuando aparecen nuevos movimientos estudiantiles en Colombia, como la Mesa Amplia Nacional Estudiantil MANE, que frenó la privatización de la educación superior y la reforma de la Ley 30 en el 2011.

Hace una semana vimos y vivimos la tercera marcha del silencio de los estudiantes colombianos. El periódico El Tiempo del 4 de octubre nos recordaba que la primera sucedió en 1948, liderada por Jorge Eliécer Gaitán para protestar contra el Gobierno por la violencia que se ejercía hacia el partido liberal y sus integrantes, y que en 1989 sucedió la segunda, cuando unos 25.000 estudiantes universitarios salieron a las calles a marchar en silencio, cansados de la violencia (Polo, 2016). La de esta semana fue para decirle Sí, con mayúsculas, a la PAZ, con mayúsculas. En estas marchas, en tres momentos distintos del país, en encuentros sin palabras donde el blanco predomina y el silencio quiere llenar el vacío, los estudiantes han reclamado la paz en nuestro país.

Los movimientos de los estudiantes son esa fuerza que desde adentro, como se llama este encuentro, buscan y reclaman por las transformaciones grandes y pequeñas. Los movimientos sociales, diría Tourine (2006), buscan las utopías, las transformaciones culturales, la liberación de los sujetos a través de una lucha ideológica contra el adversario.

No sé si podamos hablar de movimientos sociales de estudiantes de Terapia Ocupacional en Colombia; hemos tenido una Terapia Ocupacional apolítica en un mundo de contradicciones políticas y en un país marcado por la violencia política. Las historias de las terapias ocupacionales colombianas nos cuentan que son varios los intentos de organizarnos como estudiantes, que nuestras luchas han sido por la profesionalización en los setenta; por la liberación del modelo médico en los ochenta; por la búsqueda de la autonomía, el reconocimiento profesional y el cambio hacia modelos propios desde los noventa; por la apertura y la diversidad de pensamiento en este siglo XXI

Creo que es hora, y que es nuestra hora, no solo de hacer luchas hacia dentro sino desde adentro, con una proyección social justa, crítica y constructiva, es decir, con la proyección y transformación que el pueblo colombiano necesita de nosotros.

Quizás sea hora de echar mano de las ocupaciones, las nuestras, las que salen de la panza, las que vienen con el ancestro, las que cuentan las historias 
del pasado y también las que construimos para contar nuestro presente, ese que nos duele. Ocupaciones como la danza, cuando cuenta las historias de las luchas o las discriminaciones; o la de interpretar canciones que nos relatan las historias de los lugares, o poemas que sueñan con mejores futuros; las de leer o escribir novelas que nos recuerdan las historias y nos describen en ellas; todas aquellas que, como ocupaciones colectivas, contribuyen con el perdón, la paz y la reconciliación. Para tejer con puntadas finas, como lo hicieron esta semana en la Plaza de Bolívar, los buenos recuerdos, curar las heridas, conversar el ancestro y ayudar a construir un mejor lugar para nosotros y para los otros.

Quizás sea hora de promover los movimientos estudiantiles desde la Terapia Ocupacional, quizás sea hora de contribuir con otras transformaciones, y quizás sea el momento de unirnos como estudiantes, pero también como colombianos que soñamos, queremos y estamos dispuestos a tejer en un país donde es posible la paz.

Así que bienvenidos a este encuentro desde adentro, desde la madre tierra, desde la pasión que nos mueve, desde la vida que nos espera.

\section{Referencias}

Archila, M. (2012). El movimiento estudiantil en Colombia. Una mirada histórica. Revista del Observatorio Social de América Latina, (31), 71- 101.

Polo, M. (2016, 4 de octubre). Universitarios harán marcha del silencio para exigir acuerdo de paz. El Tiempo. Recuperado de http://www.eltiempo.com/politica/proceso-de-paz/marcha-universitaria-en-silencio-por-la-paz/16717850

Santamaría Sanabria, R. (S.F.). La importancia del movimiento estudiantil en las transformaciones sociales y constitucionales. Universidad del Rosario. Recuperado de http://www.urosario. edu.co/.../Ponencia_movimientos-estudiantiles-Richard-Santama.docx

Tourine, A. (2006). Podremos vivir juntos. México: Fondo Cultura Económica.

Mucha suerte y muchas gracias. 